\title{
OIL POLLUTION IN THE SOUTHEASTERN BALTIC SEA BY SATELLITE REMOTE SENSING DATA IN 2004-2015
}

\author{
Elena V. Bulycheva ${ }^{1}$, Aleksander V. Krek ${ }^{1,2}$, Andrey G. Kostianoy ${ }^{3,4,5}$, \\ Aleksander V. Semenov ${ }^{5}$, Aleksandar Joksimovich ${ }^{6}$ \\ ${ }^{1}$ Atlantic Branch of P.P. Shirshov Institute of Oceanology, Russian Academy of Sciences, \\ Kaliningrad, Russia, Prospekt Mira 1, \\ E-mail: bulycheva.lena@gmail.com \\ ${ }^{2}$ Immanuel Kant Baltic Federal University, \\ Kaliningrad, Russia, Aleksandra Nevskogo Str. 14, Build. 2, \\ E-mail: alexander.krek@gmail.com \\ ${ }^{3}$ P.P. Shirshov Institute of Oceanology, Russian Academy of Sciences, \\ Moscow, Russia, Nakhimovsky Pr. 36, \\ E-mail: kostianoy@gmail.com \\ ${ }^{4}$ Interfacultary Center for Marine Research (MARE), University of Liege, \\ Liege, Belgium, Sart Tilman, B5a, \\ E-mail: kostianoy@gmail.com \\ ${ }^{5}$ S.Yu. Witte Moscow University, \\ Moscow, Russia, Second Kozhukhovsky Pr. 12, Build. 1, \\ E-mail:semen7777@gmail.com \\ ${ }^{6}$ Institute of Marine Biology, University of Montenegro, \\ Kotor, Montenegro, P.Box 69, \\ E-mail:acojo@ac.me
}

\begin{abstract}
The results of satellite monitoring of oil pollution in the Southeastern Baltic Sea in 2004-2015 are discussed in the paper. Interannual and seasonal variability of oil pollution is investigated. A steady decrease in total oil pollution was observed from 2004 to 2011. After a sharp increase of oil pollution in 2012, oil pollution level has established at 0.39 PI Index. Maximum of oil spills is observed in the spring and summer, which is probably due to favorable weather conditions for the detection of oil spills on radar images. According to the analysis of the shapes of the detected oil spills, it was concluded that the main polluters of the sea surface are vessels. No oil spills originated from the oil platform D-6 was detected in 2004-2015. Results of numerical experiments with the Seatrack Web oil spill model show that in the case of potential discharge of oil from the D-6 platform, oil will not reach the Curonian Spit beaches during $48 \mathrm{~h}$ after an accident.
\end{abstract}

Keywords: the Southeastern Baltic Sea, oil pollution, satellite monitoring, interannual and seasonal variability of oil pollution, oil spill drift forecast

\section{Introduction}

From 2004 to present, in the framework of the complex environmental monitoring of oil field Kravtsovskoye (oil ice-resistant fixed platform (OIFP) D-6) LUKOIL-KMN, Ltd. and a number of Russian and international research projects the satellite monitoring of oil pollution at the sea surface of the Southeastern Baltic Sea is carried out (Kostianoy et al., 2004, 2005, 2006; Lavrova et al., 2011; Bulycheva, Kostianoy, 2011; Nemirovskaya et al., 2011; Kostianoy et al., 2012; Bulycheva, 2012; Kostianoy, Lavrova, 2014; Lavrova et al., 2014, Bulycheva et al., 2014, Bulycheva, Kostianoy, 2014; Kostianoy, Bulycheva, 2014; Bulycheva et. al., 2015; Ginzburg at al., 2015; Kostianoy et al., 2015; Bulycheva et. al., 2016). As part of the monitoring the following activities were performed: (1) daily operational satellite control of appearance and spreading of oil slicks on the sea surface from satellites equipped with the Synthetic Aperture Radar (SAR); (2) the determination of the likely sources of oil pollution with the Automatic Identification System (AIS); (3) forecast of the oil spill drift and transformation with the Seatrack Web operational numerical model of the Swedish Meteorological and Hydrological Institute (SMHI), which is 
recommended by HELCOM to the Baltic Sea countries; (4) collection and analysis of meteorological data, systematization and storage of the information.

The study of seasonal variability of oil pollution was made in accordance with hydrological seasons specific for the Southeastern Baltic Sea. In particular, the period from January to March is taken as winter, April-June - is spring, July-September - is summer, and October-December - is autumn (Bernikova et al., 2007).

\section{Data and Methods}

\subsection{Satellite observations}

Satellite monitoring of oil pollution on the sea surface in the Southeastern Baltic Sea is carried out from June 2004 in the framework of environmental monitoring of oilfield Kravtsovskoye (D-6) (Kostianoy et al., 2006, 2015; Bulycheva, Kostianoy, 2011, 2014; Lavrova et al., 2014). From 12 June 2004 to 31 December 2015 for the purpose of satellite monitoring the SAR images from several satellites were received and analyzed including: 1144 ASAR images from ENVISAT (European Space Agency - ESA), 298 SAR images from RADARSAT-1 (Canadian Space Agency - CSA), 425 SAR images from RADARSAT-2 (MacDonald, Dettwiler and Associates, Ltd. - MDA, Canada), 73 SAR images from satellites of the Italian Space Agency (ASI) Cosmo-SkyMED-1, -2, -3, -4, and 6 SAR images from TerraSAR-X (German Aerospace Center - DLR) (Fig. 1). Main characteristics of satellite images are given in Table 1.

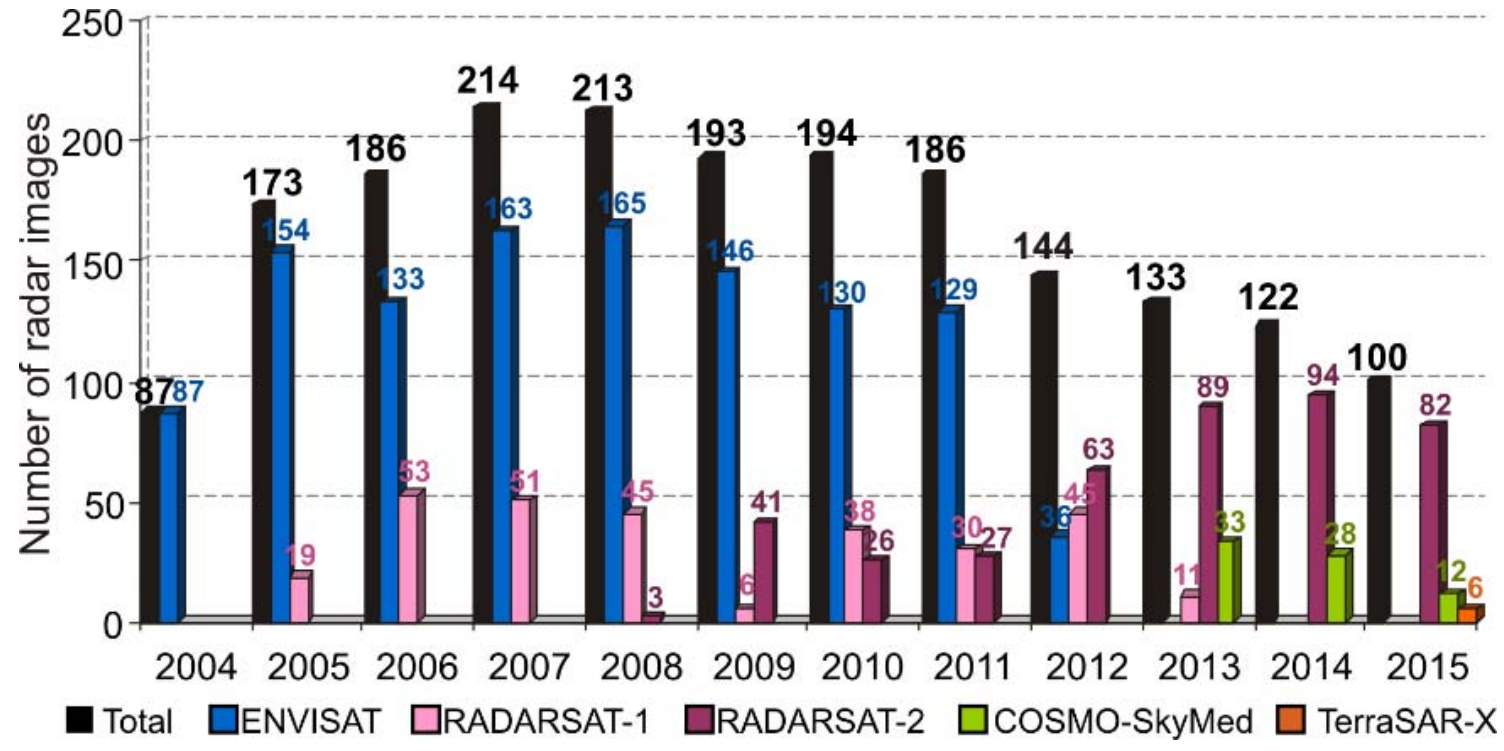

Figure 1. The number of SAR/ASAR images received from different satellites and analyzed in 2004-2015

Table 1. Main characteristics of SAR images

\begin{tabular}{|l|c|c|c|}
\hline \multicolumn{1}{|c|}{ Satellite } & Usage period & Scene size, km & Spatial resolution, m \\
\hline ENVISAT & from 01.2005 to 04.2012 & $400 \times 400$ & $150 \times 150$ \\
\hline RADARSAT-1 & from 01.2005 to 03.2013 & $300 \times 300$ & $50 \times 50$ \\
\hline RADARSAT-2 & from 12.2008 to present & $300 \times 300$ & $50 \times 50$ \\
& & $500 \times 500$ & $100 \times 100$ \\
\hline COSMO-SkyMed-1,-2,-3,-4 & from 04.2013 to present & $200 \times 200$ & $100 \times 100$ \\
\hline TerraSAR-X & from 02.2015 to present & $300 \times 300$ & $50 \times 50$ \\
\hline
\end{tabular}

These satellites are equipped with Synthetic Aperture Radar (SAR) which allows detection of spatial variability of small-scale gravity-capillary waves, which are always observed at the sea surface, as the pattern of the backscatter signal intensity distribution (SAR images). The image brightness is a reflection 
of the microwave backscattering properties of the sea surface. Films of different origin, such as oil pollution, algae blooms or ice fields, locally modify the roughness of the sea surface which is detected by the radar. The satellites provide coverage of the study area with a time interval of 12-48 hours. Advantages of the SAR method are possibilities of all-weather and round the clock acquisition of data, wide swath up to 500 $\mathrm{km}$, and high spatial resolution up to $50 \mathrm{~m}$. Limitation of the method is the condition that near-surface wind speed should be in the range of $2-10 \mathrm{~m} / \mathrm{s}$.

In case of the environmental monitoring of the oilfield Kravtsovskoye (D-6), the processed radar images were received from the Norwegian satellite operator - the Kongsberg Satellite Services (KSAT, Tromsø).

\subsection{Numerical simulation}

The interactive numerical model Seatrack Web is developed by Swedish Meteorological and Hydrological Institute (SMHI), the Danish Maritime Safety Administration (DaMSA) and Bundesamt fur Seeshiffart und Hydrographie (BSH). This tool was used for a forecast of the drift of potential leakage from D-6. Seatrack Web consist of three separate parts. The first part is the operational weather and ocean forecasting system, which provides the necessary wind and current fields. The second part is the drift, spreading and weathering model. The execution of the model is controlled by the third part of the system, which is the client/server web application.

On the basis of the most recent wind and currents forecasts, the drift model calculates the oil spill drift and spreading using a Lagrangian particle tracking technique. Weathering processes such as evaporation, vertical dispersion and formation of water-in-oil emulsions are also calculated. The results are presented on the map as particle clouds at different times along with various geographical information.

The system uses two different operational weather models ECMWF and HIRLAM (HIgh Resolution Limited Area Model, $22 \mathrm{~km}$ grid) and circulation model HIROMB (HIgh Resolution Operational Model for the Baltic sea, 24 layers, driven by the two weather models respectively), which calculates the current field at $1 \mathrm{~nm}$ grid with $15 \mathrm{~min}$ time step. The model allows to forecast the oil drift for five days ahead or to make a hindcast (backward calculation) for 30 days in the whole Baltic Sea.

\section{Results of satellite observations}

From 12 June 2004 to 31 December 20151232 oil spills were detected (Fig. 2, 3). The interannual tendency to reduction of oil pollution in the Southeastern Baltic Sea was observed from 2006 to 2011 (Fig. 2) (Bulycheva, Kostianoy, 2014). According to HELCOM, a similar trend was observed for the whole Baltic Sea in 1988-2013 (HELCOM, 2013). In 2012 an increase in the number of detected oil spills and as a result, increase of a total area of oil pollution was observed. In 2013, with a relatively small number of oil spills we have observed a high total area of oil pollution what could be explained by huge oil spills detected on 13 September 2013 and 20 September 2013 (Bulycheva, Kostianoy, 2014).

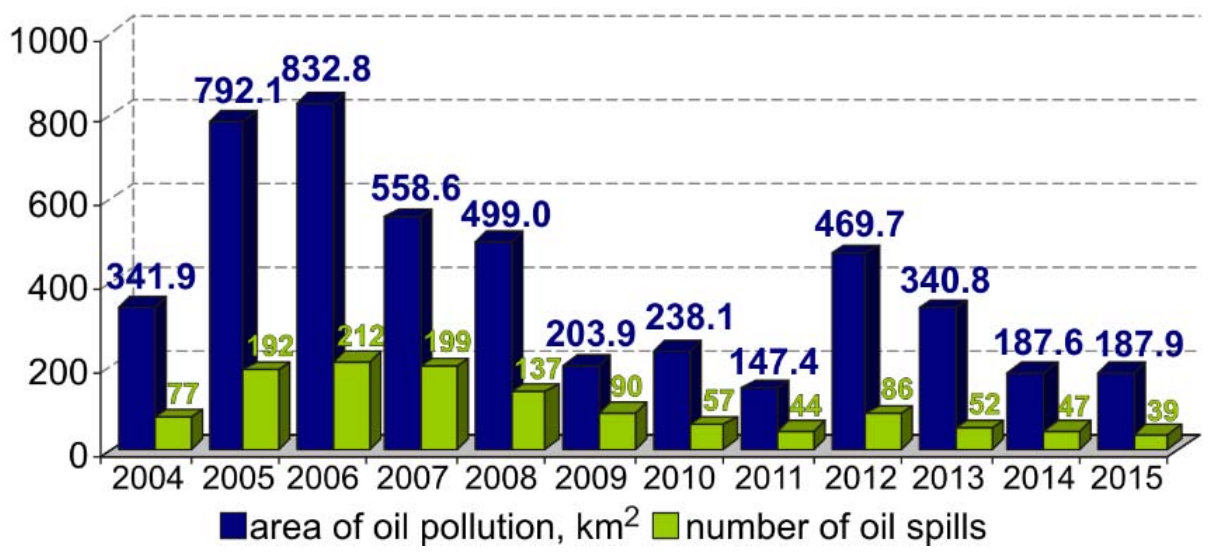

Figure 2. Interannual variability of the area of oil pollution and oil spill number for 2004-2015 




Figure 3. Summary map of oil spill detected in the result of radar images analysis and coverage of the Southeastern Baltic by satellite images from 12.06.2004 to 31.12.2015

The average area of an oil spill varies from 2.3 to $6.6 \mathrm{~km}^{2}$ (Fig. 4). There were two huge oil spills detected in September 2013 with areas of 72 and $92 \mathrm{~km}^{2}$, what make significant contribution to the average area of oil spill for 2013.

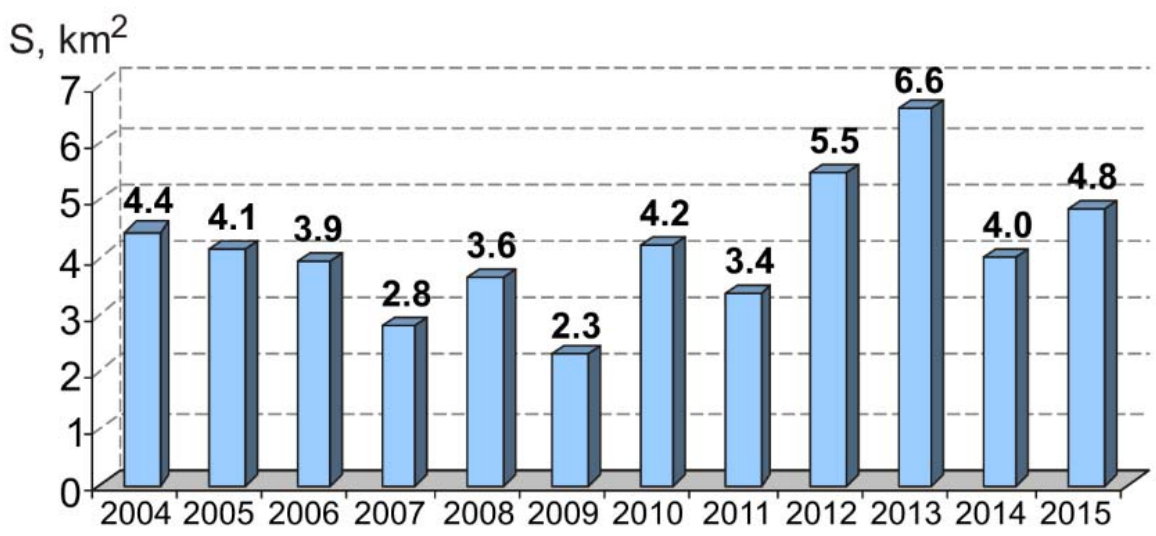

Figure 4. Interannual variability of average area of oil spill for 2004-2015

Fig. 5 shows the total number of the received satellite images and observed oil spills during 20042015. A good way to evaluate the number of illegal oil discharges is to reflect it as Pollution per satellite Image (PI) Index, which compares the total number of observed oil spills to the total number of received images (Fig. 6). Decreasing PI Index over the years indicates less oil spills observed in satellite images. A steady decline of PI Index is observed from 2006 to 2011. In 2012 a big increase in the PI Index could be seen (0.60) compared to the lowest recorded PI Index in $2011(0.24)$. This is mainly due to two huge oil spills detected in September 2013 (Bulycheva, Kostianoy, 2014, Kostianoy et al., 2015). Since 2013, the PI Index level was established at value of 0.39 (see Fig. 6). 


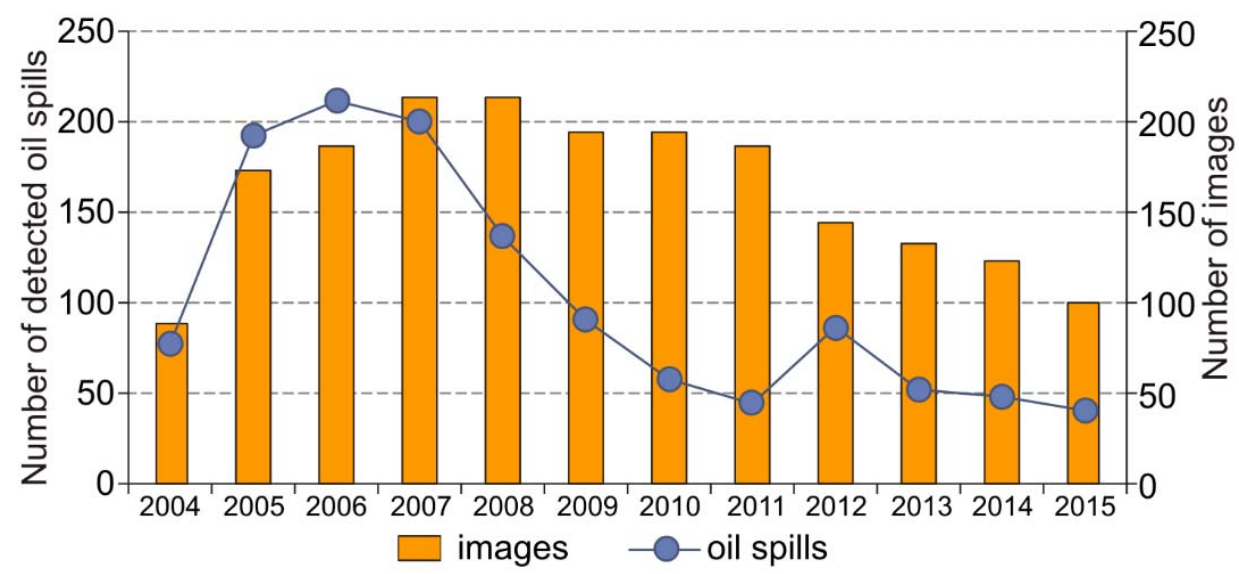

Figure 5. Total number of analyzed satellite images and detected oil spills in the Baltic Sea during 2004-2015

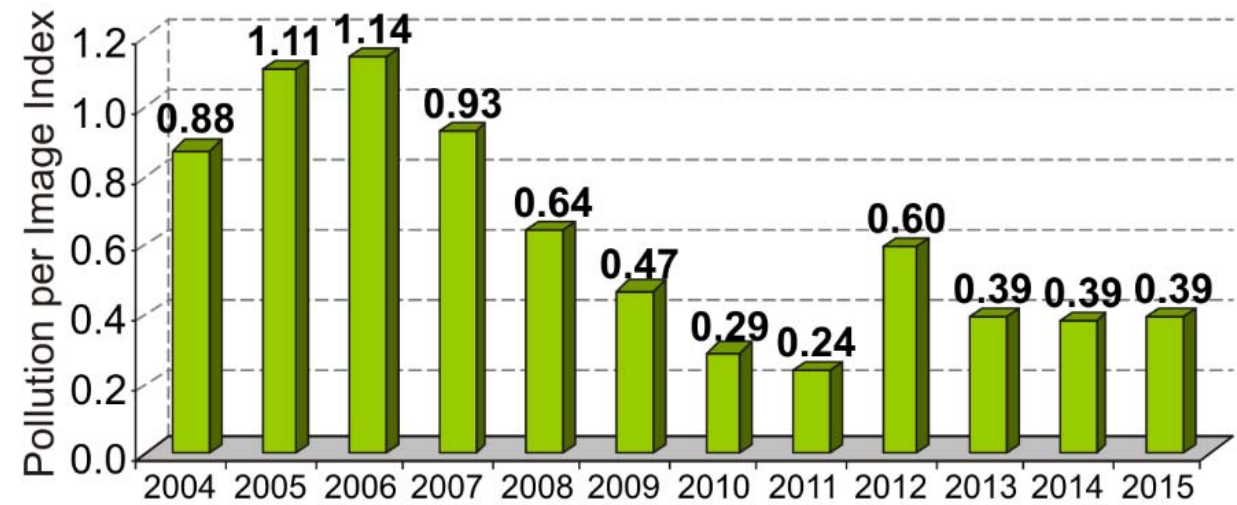

Figure 6. Interannual variability of the PI Index for 2004-2015

It was noticed that the number of the detected oil spills depends on the season. Thus, in spring and summer the number of detections is much higher than in autumn and winter (Fig. 7-8), and thus more than $83 \%$ of all oil spills were detected from March to September, what corresponds to $86 \%$ of the total area of oil spills. This is closely related to strong winds and waves prevailing in cold season, what reduces the lifetime of the oil spills and destroys gravity-capillary waves on the sea surface (Bulycheva, Kostianoy, 2014).

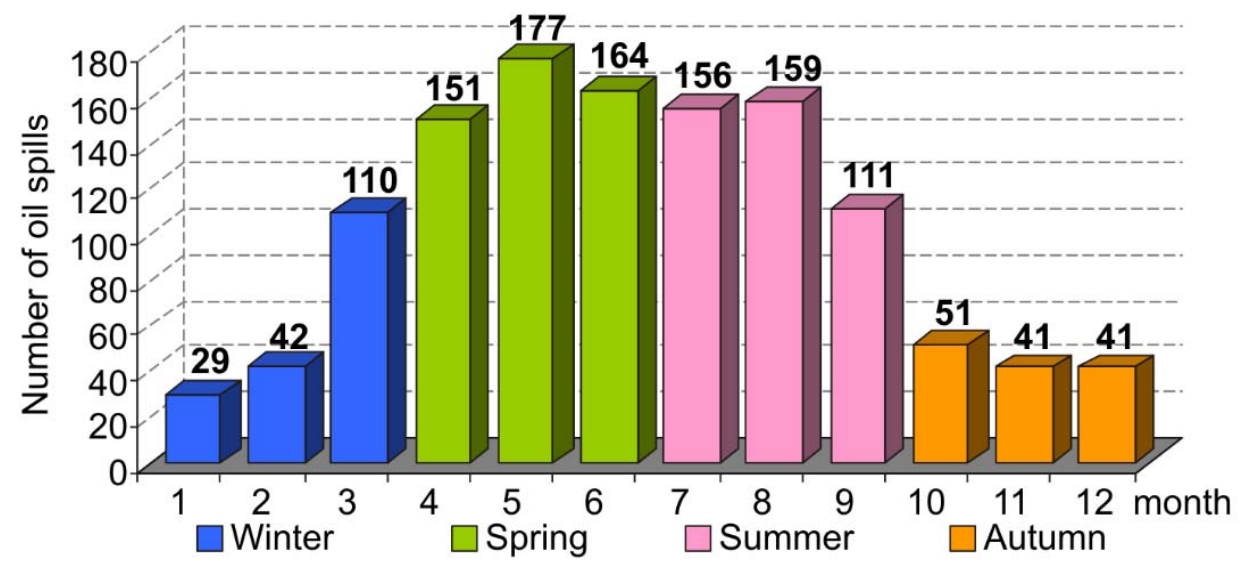

Figure 7. Seasonal variability of the number of detected oil spills from 12.06.2004 to 31.12.2015 


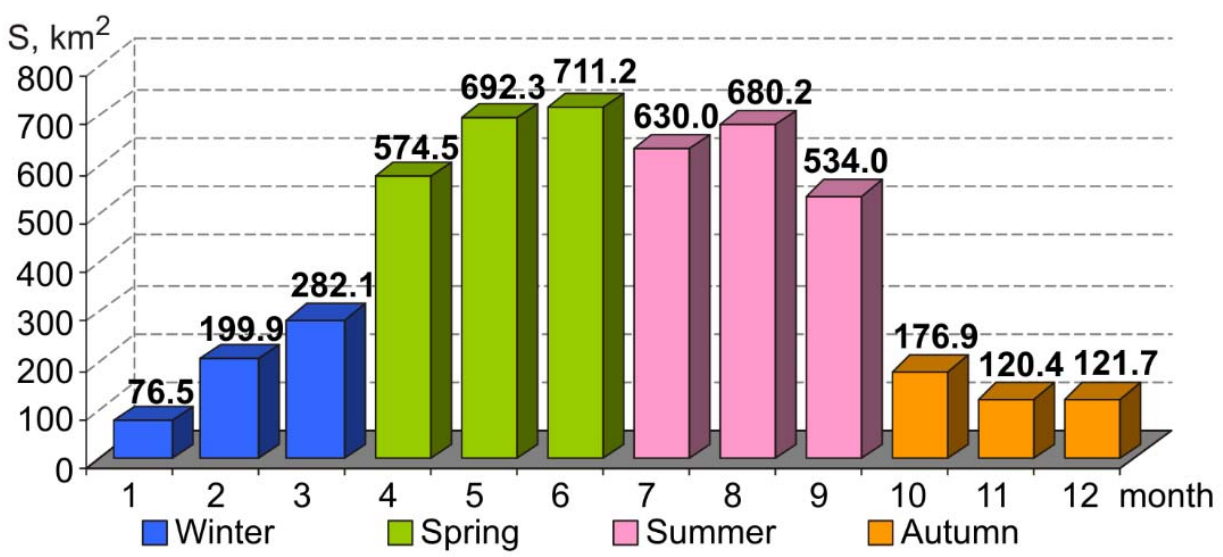

Figure 8. Seasonal variability of the oil pollution area observed by satellite radar data from 12.06.2004 to 31.12.2015

The majority of all detected all spills are located along the main shipping routes in the Baltic Sea (Fig. 9). For the Swedish EEZ there are two main traffic lines south-east from Gotland Island. Tail shaped spills are prevailed in these areas and in the whole Baltic Sea (Fig. 10). The analysis of the shapes and concentration of oil spills with the location of the main shipping routes based on the AIS for the Baltic Sea led us to a conclusion that the main source of oil pollution are ships of a different type (Kostianoy and Lavrova, 2014; Bulycheva and Kostianoy, 2014; Kostianoy et al., 2015, Kostianoy et al., 2015). A lot of patch shaped spills were observed in the area of anchorage near the Port of Baltyjsk. This shape of the spills is a characteristic feature of a discharge from the stationary ship. The sources of oil spills in the areas with low density of AIS signals are small fishing ships not equipped with the AIS (Bulycheva et al., 2014).

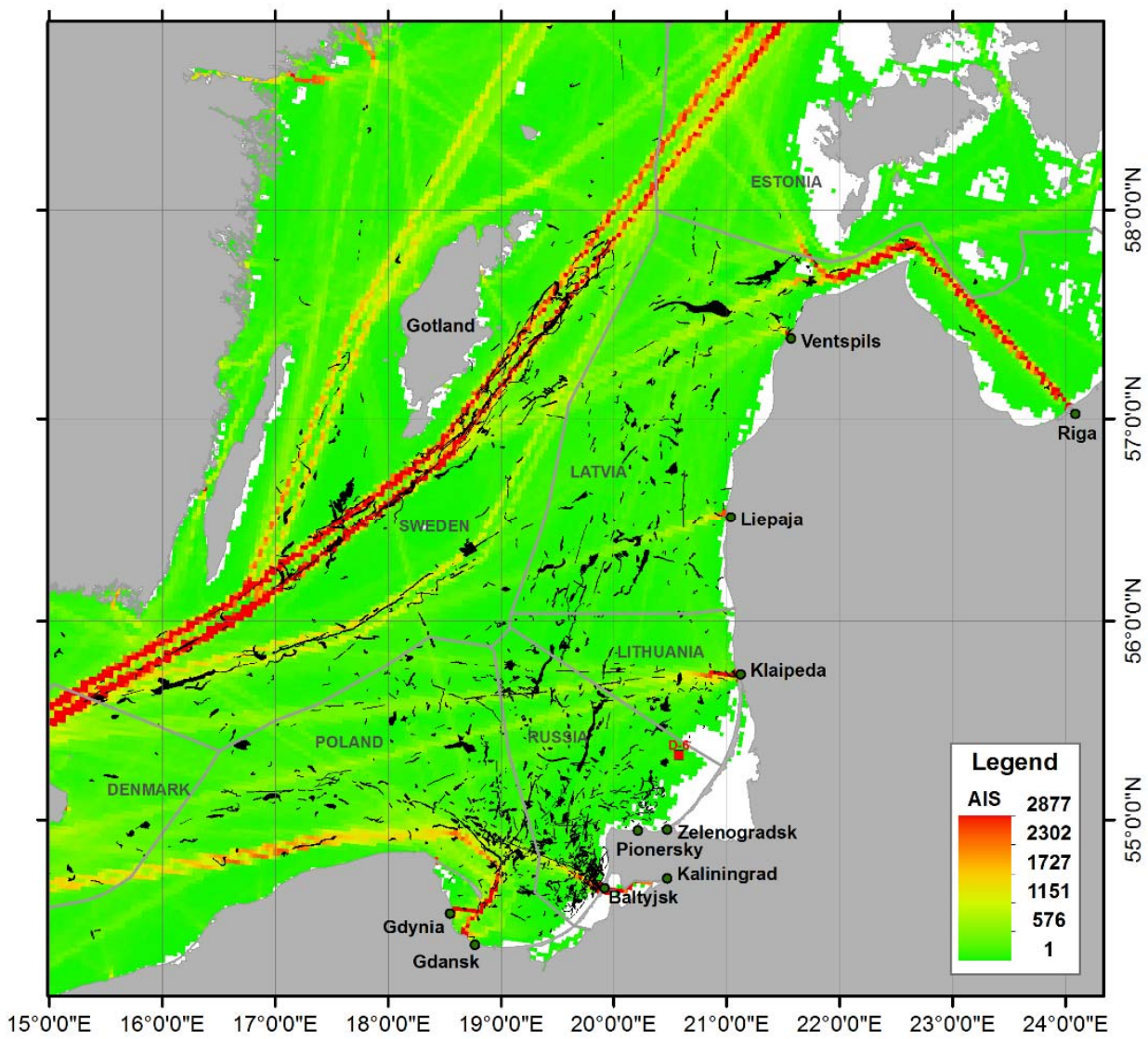

Figure 9. Density of the AIS signals according to (HELCOM, 2011) and oil spills detected from 12 June 2004 to 31 December 2015 


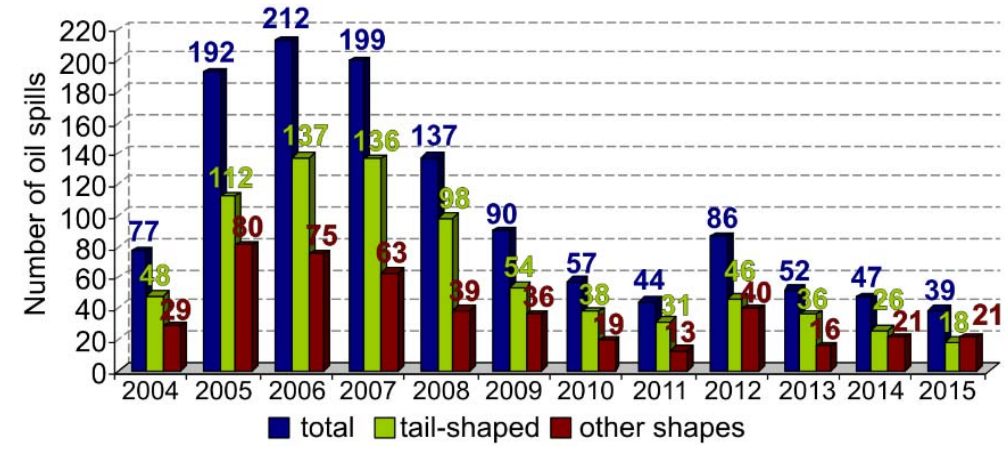

(a)

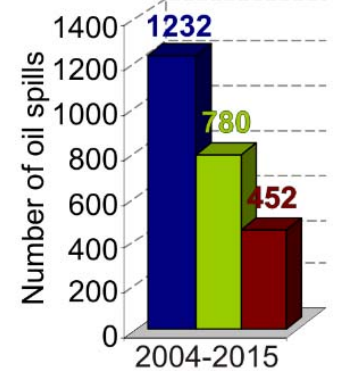

(b)

Figure 10. Shape of oil spills detected from 12 June 2004 to 31 December 2015: (a) interannual; (b) total

\section{Numerical modeling of risks of oil pollution caused by potential accident at D-6 oil rig}

The results of the direct daily forecasts for 48 hours from 01.01 .2015 to 31.12 .2015 , based on the Seatrack Web model, show that in the case of a potential accident on the platform D-6 oil in the most cases will drift to the northeast, east, and in a few cases to the south. At the same time, in any case the oil will not reach the coast of the Curonian Spit during next $48 \mathrm{~h}$ after a potential accident (Fig. 11). The main directions of the oil spill drift are in a good agreement with the data of automatic hydrometeorological station (AHMS) installed on D-6 platform (Fig. 12).

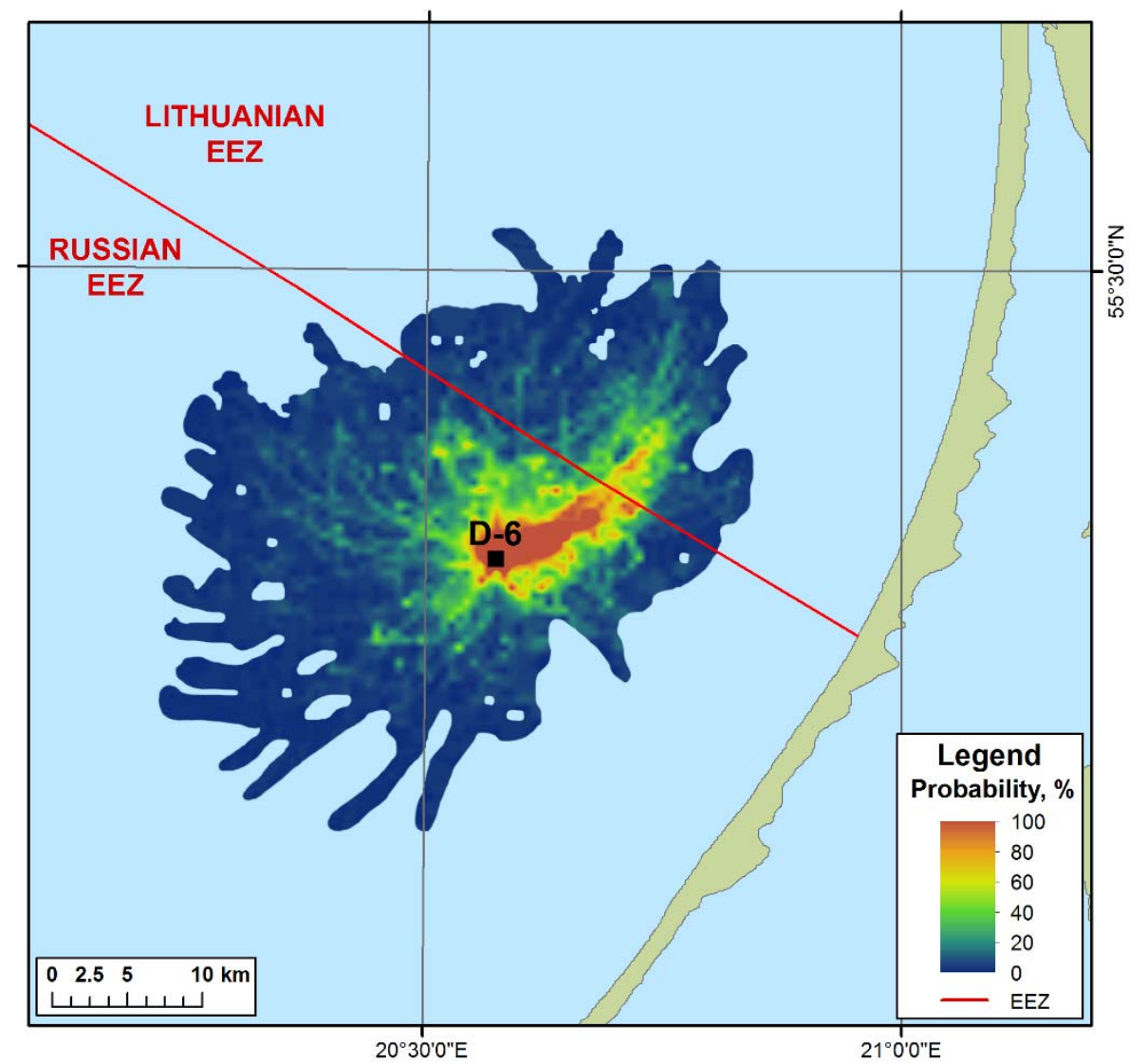

Figure 11. Probability of oil pollution propagation (\%) during $48 \mathrm{~h}$ after a potential accident at D-6 oil rig for 2015 , calculated by the Seatrack Web numerical model 


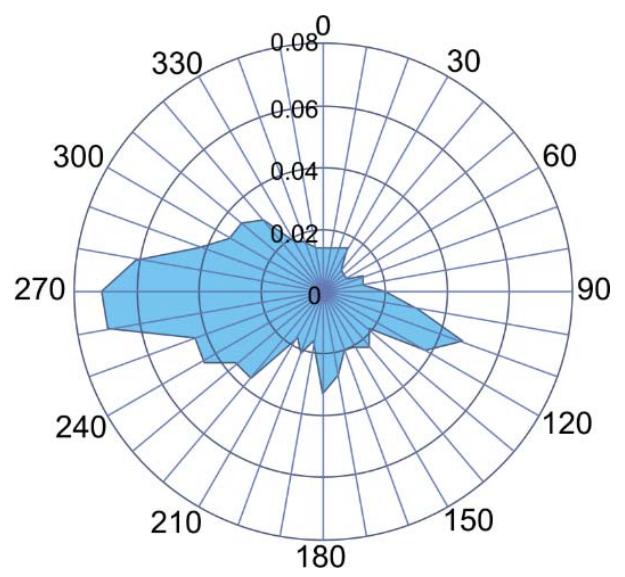

Figure 12. Wind rose in 2015 by AHMS on D-6 platform

\section{Conclusions}

Nowadays satellite monitoring of the oil pollution at the sea surface of the Southeastern Baltic is the only tool of control of illegal discharges in the Russian part of the Southeastern Baltic Sea, as no State monitoring is conducted. From the beginning of satellite observations, the number of the detected oil spills and the oil pollution area has decreased till 2011. In 2013-2015 the uniform low level of oil pollution is observed.

Majority of oil spills are located along the mail shipping routes in the Baltic Sea. The most polluted area of the Baltic Proper is navigational routes eastward from Gotland Island. The main approaches to the Ports of Klaipeda and Ventspils are outlined by tail-shaped oil spills. In the Russian part of the Southeastern Baltic Sea illegal discharges occur westward from Sambia Peninsula near the Port of Baltiysk. For 2004-2015 no contamination from the D-6 oil platform was recorded.

The largest number of oil spills in the Southeastern Baltic Sea was observed in spring and summer time, what can be explained by the restrictions of the applied SAR method.

As a result of numerical simulation of potential accident on the D-6 oil platform we showed that the oil will drift mainly to the northeast and east. But, no one case of contamination of the Curonian Spit beaches during $48 \mathrm{~h}$ after a potential discharge from the D-6 platform in 2015 was forecasted by the Seatrack Web model.

\section{Acknowledgements}

The authors would like to thank LUKOIL-KMN, Ltd. for providing of satellite radar imagery. E.V. Bulycheva conducted interannual variability of oil pollution by satellite data in the framework of the State Assignment of the Federal Agency for Scientific Organizations N 0149-2014-0040. A.V. Krek was engaged in numerical simulation of potential oil spill discharge from the D-6 oil platform in the framework and with a support of the Russian Science Foundation Project N 14-37-00047. A.G. Kostianoy conducted a study of seasonal variability of oil pollution by satellite data in the framework and with a support of the Russian Science Foundation Project N 14-50-00095. The research by A.G. Kostianoy was partially done in the framework of collaboration with Dr. Marilaure Grégoire from the Interfacultary Center for Marine Research (MARE) and Modelling for Aquatic Systems (MAST), University of Liège, Belgium.

\section{References}

1. Bernikova, T.A., Dubravin, V.F., Nagornova, N.N., and Stont, Zh.I. (2007) The climatic seasons of the Southern Baltic. Proc. V International scientific conference "Innovations in science and education - 2007". Kaliningrad, Kaliningrad State Technical University, Part 1, 53-55 (in Russian).

2. Bulycheva E.V. (2012) Oil pollution of the sea surface in 2006-2009 based on satellite radiolocation), In book: Oil andenvironment of Kaliningad Region. Vol. 2: The Sea. Kaliningrad, «Yantarnyj skaz», pp. 518-529. 
3. Bulycheva, E.V., Kostianoy, A.G. (2011) Results of the satellite monitoring of oil pollution in the Southeastern Baltic Sea in 2006-2009. Modern problems of remote sensing of the Earth from space, V8, N 2, 74-83 (in Russian).

4. Bulycheva, E.V., Kostianoy, A.G. (2014) Results of satellite monitoring of the sea surface oil pollution in the Southeastern Baltic Sea in 2004-2013. Modern problems of remote sensing of the Earth from space, V11, N 4, 111-126 (in Russian).

5. Bulycheva, E., Kuzmenko, I., and Sivkov, V. (2014) Annual sea surface oil pollution of the southeastern part of the Baltic Sea by satellite data for 2006-2013. Baltica, V27, Special Issue, 9-14.

6. Bulycheva E.V., Krek A.V., Kostianoy A.G., Semenov A.V., Joksimovich A. (2015) Oil Pollution of the Southeastern Baltic Sea by satellite remote sensing data and in-situ measurements. Transport and Telecommunication, V.16, N4, P. 296-304.

7. Bulycheva E.V., Krek A.V., Kostianoy A.G. (2016) Oil pollution in the Southeastern Baltic Sea by satellite data and in-situ observations. Okeanologia, V.56, N 1, pp.1-10 (in Russian).

8. Ginzburg, A.I., Bulycheva, E.V., Kostianoy, A.G., Soloviev, D.M. (2015) About role of eddies in propagation of oil pollution in Southeastern Baltic (by data of sateliite monitoring). Modern problems of remote sensing of the Earth from space, Vol. 12, N 3, pp. 149-157.

9. HELCOM (2013) Illegal discharges observed during aerial surveillance 2013. Source: http://www.helcom.fi/Lists/Publications/HELCOM/report/202013.pdf

10. Kostianoy, A.G., Bulycheva, E.V. (2014) Numerical simulation of risks of oil pollution in the Southeastern Baltic Sea and in the Gulf of Finland. Modern problems of remote sensing of the Earth from space, V11, N 4, 56-75 (in Russian).

11. Kostianoy, A.G., Bulycheva, E.V., Semenov, A.V., and Krainyukov, A.V. (2015) Satellite monitoring systems for shipping, and offshore oil and gas industry in the Baltic Sea. Transport and Telecommunication, V16, N2, 117-126.

12. Kostianoy A.G., Lebedev S.A., Litovchenko K.Ts., Stanichny S.V., Pichuzhkina O.E. Satellite remote sensing of oil spill pollution in the southeastern Baltic Sea, Gayana, 2004, Vol. 68, N 2, Part 2, 327-332.

13. Kostianoy, A.G., Lebedev, S.A., Soloviev, D.M., Pichuzhkina, O.E. (2005) Satellite monitoring of the Southeastern Baltic Sea. Annual Report 2004, Kaliningrad: Lukoil-Kaliningradmorneft, 36 pp.

14. Kostianoy, A.G., Litovchenko, K.Ts., Lavrova, O.Yu., Mityagina, M.I., Bocharova, T.Yu., Lebedev, S.A., Stanichny, S.V., Soloviev, D.M., Sirota, A.M., and Pichuzhkina, O.E. (2006) Operational satellite monitoring of oil spill pollution in the southeastern Baltic Sea: 18 months experience. Environmental Research, Engineering and Management, N4(38), 70-77.

15. Kostianoy A.G., Litovchenko K.C., Lavrova O. Yu., Mitiagina M.I., Bocharova T.Yu., Lebedev S.A., Stanichny S.V., Solovjev D.V., Sirota A.M. (2012) Integrated operational satellite monitoring in 2004-2005, In book: Oil and environment of Kaliningad Region. Vol. 2: The Sea. Kaliningrad, «Yantarnyj skaz», 483-518.

16. Lavrova, O.Yu., Kostianoy, A.G., Lebedev, S.A., Mitiagina, M.I., Ginzburg, A.I., Sheremet, N.A. (2011) Integrated satellite monitoring of Russian seas, Moscow: IKI RAN, 470 p.

17. Lavrova, O.Yu., Mityagina, M.I., Kostianoy, A.G., and Semenov, A.V. (2014) Oil pollution in the southeastern Baltic Sea in 2009-2011. Transport and Telecommunication, V15, N4, 322-331.

18. Nemirovskaya, I.A., Sivkov, V.V., Bulycheva, E.V. (2011) Content and composition of hydrocarbons in the Kravtsovskoe oil field region, the Baltic Sea, Reports of RAS, pp. 520-525. (in Russian). 